\title{
HISTOPATHOLOGICAL SPECTRUM OF ORAL CAVITY LESIONS
}

\author{
Ritu Bhagat ${ }^{1}$, Mandeep Randhawa², Subhash Bhardwaj ${ }^{3}$
}

${ }_{1}^{1}$ Senior Resident, Department of Pathology, GMC, Jammu, Jammu and Kashmir, India.

${ }^{2}$ Assistant Professor, Department of Pathology, GMC, Amritsar, Punjab, India.

3Professor, Department of Pathology, GMC, Jammu, Jammu and Kashmir, India.

\section{BACKGROUND}

ABSTRACT

Oral cancer is a common problem in the Indian region, and it is one of top three cancers in our country. Many epidemiological studies have concluded that excess intake of alcohol and tobacco leads to increased risk of oral cavity cancers. In addition to this, in India there is a high prevalence of chewing tobacco mixtures. The oral cavity represents the entrance to the upper aerodigestive tract, which begins at the lips and ends at the anterior surface of the faucial arch. It is lined by squamous epithelium with interspersed minor salivary glands. The oral cavity is continuously exposed to inhaled and consumed carcinogens and thus it is the most common site for the origin of malignant epithelial neoplasms in the head and neck region. Known carcinogens in the oral cavity include those present in tobacco, alcohol, and betel nuts. The association of human papilloma virus with oral cancer is not as well established as in oropharyngeal cancers. Primary tumours of oral cavity may arise from the surface epithelium, minor salivary glands, or submucosal soft tissues. More than $90 \%$ of malignant tumours in oral cavity are squamous cell carcinomas, and the remainder are minor salivary gland carcinomas and other rare tumours. Most patients with cancer in oral cavity are men, although the incidence of tongue cancer in women in the United States has progressively increased from 15\% in the years 1927-1934 to 4\% in the years 1988-1997. In the western world, the tongue and the floor of the mouth are the most common sites of origin for primary squamous cell carcinoma in the oral cavity. However, the retromolar trigone and buccal mucosa are the most frequently encountered primary sites in the area of world where chewing of tobacco and betel nuts is common. ${ }^{1}$ We wanted to study the different types of oral cavity lesions.

\section{METHODS}

This is a prospective study performed in pathology department of GMC Jammu, a tertiary care hospital in Jammu for a duration of one year, from January 2018 to January 2019. A total of 114 cases were studied.

\section{RESULTS}

A total of 103 cases were studied. Age of patients varied from 6 to 75 years, out of which males were affected more often than females with M: F ratio of 4:1. The most common site involved was buccal mucosa (30.1\%), followed by tongue (28\%). Out of 103 cases 77 cases $(74.7 \%)$ were malignant and 26 cases (25.2\%) were benign. Squamous cell carcinoma is the most common lesion accounting for $67.9 \%$ cases of all the lesions studied.

\section{CONCLUSIONS}

Oral cavity lesions have a vast spectrum of lesions ranging from tumour like lesions to benign and malignant tumours. Our study concluded that squamous cell carcinoma was the most common malignant lesion of oral cavity. Histopathology is an important tool in the diagnosis and management.

\section{KEY WORDS}

Oral Cavity, Buccal Mucosa, Squamous Cell Carcinoma

HOW TO CITE THIS ARTICLE: Bhagat R, Randhawa M, Bhardwaj S. Histopathological spectrum of oral cavity lesions. J. Evolution Med. Dent. Sci. 2019;8(24):1886-1890, DOI: $10.14260 /$ jemds/2019/415

\section{BACKGROUND}

The oral cavity represents the entrance to the upper aerodigestive tract, which begins at the lips and ends at the anterior surface of the faucial arch. It is lined by squamous epithelium with interspersed minor salivary glands. The oral cavity is continuously exposed to inhaled and consumed carcinogens and thus it is the most common site for the origin of malignant epithelial neoplasms in the head and neck region.

'Financial or Other Competing Interest': None.

Submission 12-04-2019, Peer Review 03-06-2019,

Acceptance 10-06-2019, Published 17-06-2019.

Corresponding Author:

Dr. Mandeep Randhawa,

Assistant Professor, Department of Pathology,

GMC, Amritsar, Punjab, India.

E-mail: mandyrandhawa26@gmail.com

DOI: $10.14260 /$ jemds $/ 2019 / 415$
Known carcinogens in the oral cavity include those present in tobacco, alcohol, and betel nuts. The association of human papilloma virus with oral cancer is not as well established as in oropharyngeal cancers. Primary tumours of oral cavity may arise from the surface epithelium, minor salivary glands, or submucosal soft tissues. More than $90 \%$ of malignant tumours in oral cavity are squamous cell carcinomas, and the remainder are minor salivary gland carcinomas and other rare tumours. Most patients with cancer in oral cavity are men, although the incidence of tongue cancer in women in the United States has progressively increased from $15 \%$ in the years $1927-1934$ to $4 \%$ in the years 1988-1997. In the western world, the tongue and the floor of the mouth are the most common sites of origin for primary squamous cell carcinoma in the oral cavity. However, the retromolar trigone and buccal mucosa are the most frequently encountered primary sites in the area of 
world where the chewing of tobacco and betel nuts is common. ${ }^{1}$

Oral cancer is a major health problem in the Indian region and it is one of the top three cancers of the country. ${ }^{2}$ Many epidemiological studies have concluded that excess intake of alcohol and tobacco can lead increased risk of developing oral and pharyngeal tumours. ${ }^{3}$ Also in India there is high prevalence of chewing tobacco mixtures. 4

Oral cavity lesions are usually common but ignored. They may be benign or malignant. Common benign lesions are lymphoid hyperplasia, retention cyst, inflammation, haemangioma, fibroma etc. And among malignant lesions Squamous cell carcinoma is the most common. Oral cancer ranks $8^{\text {th }}$ most common cancer worldwide and $3^{\text {rd }}$ most common cancer in India. Age standardized incidence rate of oral cancer is 12.6 per 100,000 population. 5

In spite of easy reach to oral cavity lesions for direct examination these malignancies still remain undetected for a long time, until a late stage and the survival rate for oral cancer has remained essentially unchanged over the past three decades. Proper management of the patient with the premalignant and malignant oral lesions starts with an accurate diagnosis. Histopathologic assessment of a tissue biopsy of the lesion is a standard method for diagnosis of suspicious lesion. 6

\section{Aim of The Study}

The present study was undertaken to study the different types of oral cavity lesions.

\section{METHODS}

This study included 103 specimens of lesions of oral cavity which were sent to department of pathology of GMC Jammu, a tertiary care hospital of Jammu region for histopathology from January 2018 to January 2019. Sample size was taken based on the convenience of the study. Our study was a prospective study in which data like age of patient, sex and site of lesion were noted from the clinical data of the patients. Got approval from IEC and consent was taken from all patients.

\section{Statistical Analysis}

The data was collected and analysed using standard statistical chi-square test, $\mathrm{P}<0.05$ statistically significant. Data was entered in Microsoft excel and analysis was done using SPSS version 22.

\section{RESULTS}

A total of 103 cases of oral cavity lesions were studied. The age varied from 6 years to 75 years. A six-year-old male child with chronic tonsillitis was the youngest patient and the 75 years old male with Squamous cell carcinoma of buccal mucosa was the oldest one. Majority of patients were in the age range of 20-40 years followed by 40-60 years. Among 103 cases 77 (74.7\%) cases were malignant and 26 (25.2\%) cases were benign. Out of total 103 cases, 84 (81.5\%) were males and 20 (19.4\%) were females with a Male: Female ratio of $4: 1$. Commonest clinical presentation of oral lesion were ulcero-proliferative growth, ulcers, nodular growth and proliferative growth.

\begin{tabular}{|c|c|c|c|}
\hline Sl. No. & Sex & Number & Percentage \\
\hline 1. & Male & 84 & $81.5 \%$ \\
\hline 2. & Female & 20 & $19.4 \%$ \\
\hline \multicolumn{3}{|c|}{ Table 1. Sex Distribution } \\
\hline In our study out of 103 cases, there were 81.5\% males and $19.4 \%$ females.
\end{tabular}

\begin{tabular}{|c|c|c|c|}
\hline Sl. No. & Site & Number & Percentage \\
\hline 1. & Buccal mucosa & 31 & $30.1 \%$ \\
\hline 2. & Tongue & 29 & $28 \%$ \\
\hline 3. & Tonsil & 15 & $14.5 \%$ \\
\hline 4. & Palate & 13 & $12.6 \%$ \\
\hline 5. & Gingiva & 05 & $4.8 \%$ \\
\hline 6. & Lip & 04 & $3.8 \%$ \\
\hline 7. & Alveolus & 02 & $1.9 \%$ \\
\hline 8. & Mandible & 02 & $1.9 \%$ \\
\hline 9. & Angle of mouth & 01 & $0.9 \%$ \\
\hline 10. & Maxilla & 01 & $0.9 \%$ \\
\hline & Total & $\mathbf{1 0 3}$ & $\mathbf{1 0 0} \%$ \\
\hline
\end{tabular}

Table 2. Number of Cases According to Sites

The sites of involvement of various lesions included buccal mucosa 31 $(30.1 \%)$, tongue $29(28 \%)$, tonsil $15(14.5 \%)$, palate $13(12.6 \%)$, gingiva 05 (4.8\%), lip 04 (3.8\%), alveolus and mandible $02(1.9 \%)$ cases each, maxilla and angle of mouth $01(0.9 \%)$ cases each.

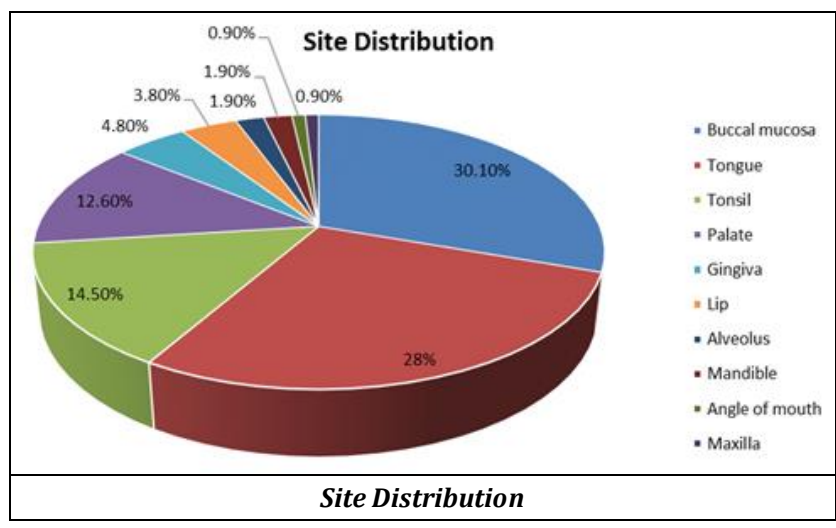

\begin{tabular}{|c|c|c|c|}
\hline Sl. No. & Diagnosis & Number & Percentage \\
\hline 1. & Squamous cell carcinoma & 70 & $67.9 \%$ \\
\hline 2. & Haemangioma & 06 & $5.8 \%$ \\
\hline 3. & Chronic tonsillitis & 05 & $4.8 \%$ \\
\hline 4. & Chronic inflammation & 02 & $1.9 \%$ \\
\hline 5. & Squamous papilloma & 03 & $2.9 \%$ \\
\hline 6. & Verrucous carcinoma & 02 & $1.9 \%$ \\
\hline 7. & Fibrolipoma & 02 & $1.9 \%$ \\
\hline 8. & Ameloblastic carcinoma & 02 & $1.9 \%$ \\
\hline 9. & Epulis & 02 & $1.9 \%$ \\
\hline 10. & Lichen planus & 02 & $1.9 \%$ \\
\hline 11. & Pleomorphic adenoma & 01 & $0.9 \%$ \\
\hline 12. & Adenoid cystic carcinoma & 01 & $0.9 \%$ \\
\hline 13. & Lymphangioma & 01 & $0.9 \%$ \\
\hline 14. & Basal cell carcinoma & 01 & $0.9 \%$ \\
\hline 15. & Angiofibroma & 01 & $0.9 \%$ \\
\hline 16. & Fibrous histiocytoma & 01 & $0.9 \%$ \\
\hline 17. & NHL & 01 & $0.9 \%$ \\
\hline & Total & $\mathbf{1 0 3}$ & $\mathbf{1 0 0} \%$ \\
\hline
\end{tabular}

Table 3. Types of Neoplastic and Non-Neoplastic Lesions of Oral Cavity

The various lesions have been depicted in table 3 .

In our study majority of cases were of Squamous cell carcinoma constituting $67.9 \%$ cases, Haemangioma $5.8 \%$ cases, chronic tonsillitis $4.8 \%$ cases, chronic inflammation $1.9 \%$ cases, squamous papilloma $2.9 \%$ cases, verrucous carcinoma, fibrolipoma, ameloblastic carcinoma, epulis

and lichen planus constituting $1.9 \%$ cases each respectively and pleomorphic adenoma, adenoid cystic carcinoma, lymphangioma, basal cell carcinoma, angiofibroma, fibrous histiocytoma and NHL constituting $0.9 \%$ cases each respectively. 

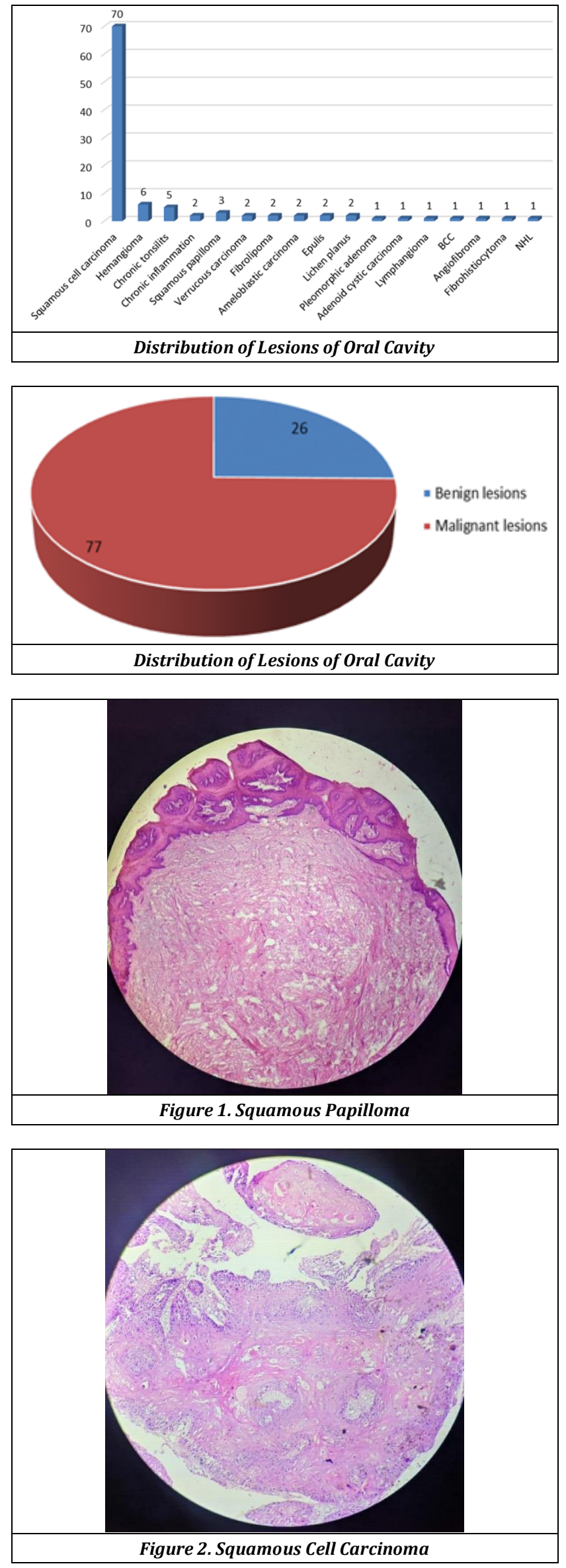
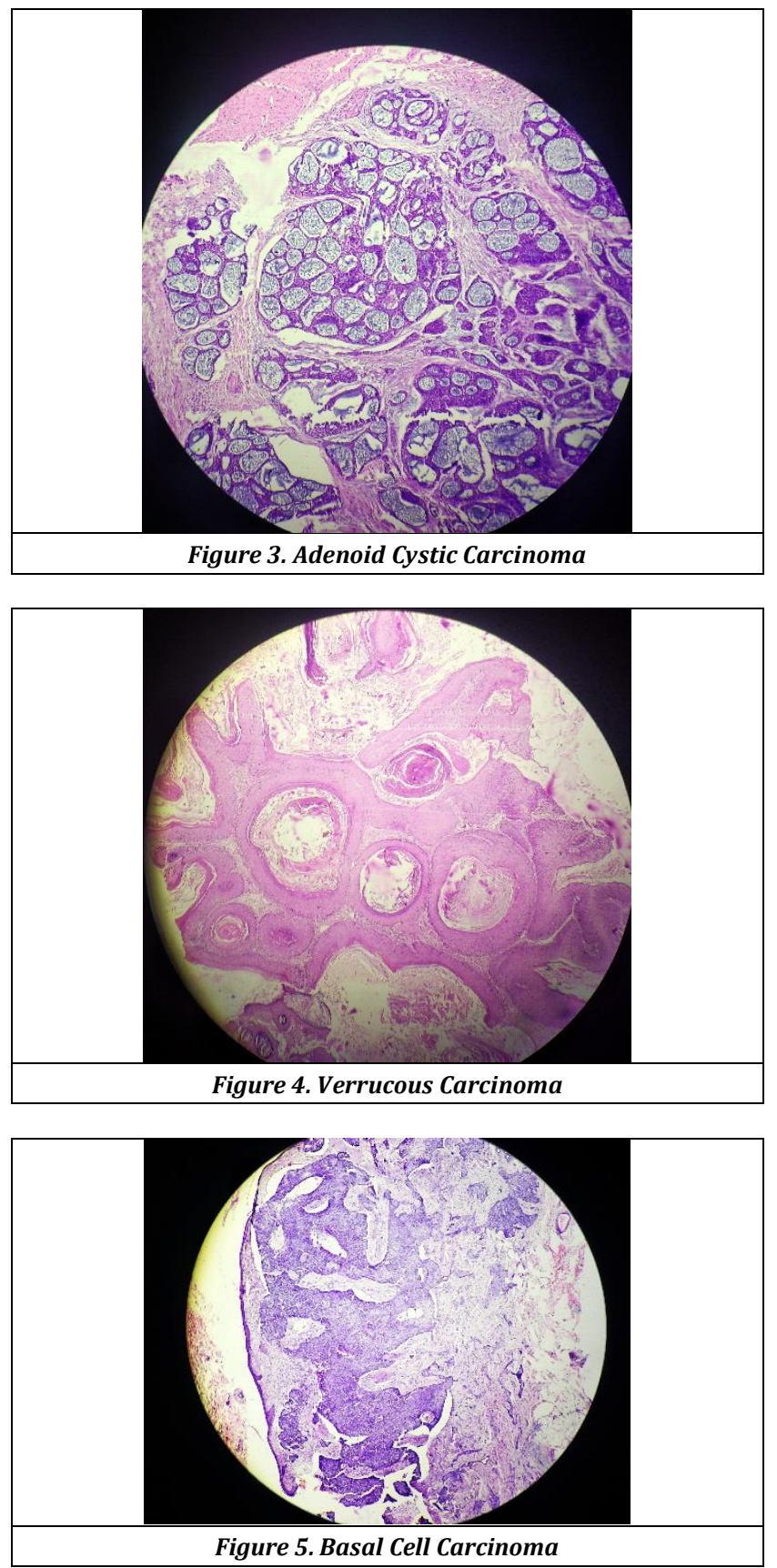

\section{DISCUSSION}

In our study of total 103 cases, male to female ratio was 4:1. This indicates that premalignant and malignant lesions are more common in males than females, the reason for this is excess intake of alcohol and tobacco by males than females in India. In study by Palve et al. 7 60\% cases were males and females were $40 \%$ out of total 50 cases with M: F ratio of 3:2, which is similar to our finding. Male preponderance also reported in studies by Senguven et al. ${ }^{8}$ and Pudasaini et al. ${ }^{9}$

Buccal mucosa $(30.1 \%)$ was the most common site involved in our study, followed by tongue (28\%), tonsil $(14.5 \%)$, palate $(12.6 \%)$, gingiva (4.8\%) and lip (3.8\%). Modi et al. 10 also reported similar findings where buccal mucosa constituted (26.8\%), tongue (26.1\%), hard palate $(12.6 \%)$ gingiva (2\%) and lip (6.7\%). Findings by Mehta et al.11 were buccal mucosa (32\%), tongue (19\%), gingiva (3\%), lip (22\%), and hard palate $(2 \%)$. Buccal mucosa was the most frequently 
involved site followed by tongue of benign and premalignant lesions in study by Mehrotra et al. ${ }^{12}$

Most lesions of squamous cell origin have a varying degree of histological progression from in situ to invasive carcinoma. The histological grade of the lesion generally reflects the aggressiveness of the tumour. Squamous cell carcinoma may range from well differentiated to poorly differentiated as well as undifferentiated and sarcomatoid, as defined by the extent to which tumour differentiates nuclear pleomorphism, cytological atypia, and morphological resemblance to benign squamous mucosa. The histological grade reflects the aggressiveness of the tumour. Tumours that are undifferentiated or sarcomatoid are the most aggressive. The most important histological feature of the primary tumour that affects selection of treatment and eventual prognosis is its depth of infiltration. ${ }^{1}$

In our study squamous cell carcinoma (67.9\%) was the most common lesion. The most common site was buccal mucosa followed by tongue. Similar results were seen in studies by Misra et $\mathrm{al}^{13}$ and Hassawi et al ${ }^{14}$ who reported $60.12 \%$ and $58.9 \%$ respectively.

In our study, haemangioma was observed was in $5.8 \%$ cases, similar result was seen in study by Sharma et al. ${ }^{15}$ with $5.3 \%$ cases.

Squamous papilloma was reported in $2.9 \%$ cases in our study, similarly Sharma et al. 15 reported $3.3 \%$ and Mehta et al. $112 \%$ cases.

Lichen planus was reported in $1.9 \%$ cases, but Sharma et al. ${ }^{15}$ reported a slightly low incidence with $0.6 \%$ cases.

In our study chronic inflammation was observed in $1.9 \%$ cases, which is similar to results of Kosam et al. $162 \%$ and Sharma et al. ${ }^{15}$ with $0.6 \%$ cases.

Verrucous carcinoma is a variant of Squamous cell carcinoma. It appears as a white plaque over the mucosa. In our study there were 2 cases (1.9\%), these results are in accordance with Kosam et al. ${ }^{16} 1.4 \%$, Durazzo et al. 17 1.1 \%, Bhattacharjee et $\mathrm{al}^{18} 0.62 \%$, and Bal et $\mathrm{al}^{19} 1.9 \%$.

Adenoid cystic carcinoma was reported in $0.9 \%$ cases, similar findings were seen in studies by Bhattacharjee et al. ${ }^{18}$ 0.93\%, Bal et al. ${ }^{19}$ 1\%, Manjari et al ${ }^{20} 1.71 \%$ and Shah et al.21 with $1.33 \%$ cases.

One case of non-Hodgkin lymphoma $(0.9 \%)$ was seen in our study, similar result seen in study by Manjari et al.20 $0.38 \%$ and shah et al. ${ }^{21} 2.67 \%$ cases.

In our study one case $(0.9 \%)$ of pleomorphic adenoma was seen similar results seen in study by Sharma et al. ${ }^{15}$ with $0.6 \%$.

One case $(0.9 \%)$ of lymphangioma was observed in our study, similar results of $1.3 \%$ cases were seen in study by Sharma et al. 15

\section{CONCLUSIONS}

Oral cavity lesions include a wide spectrum of lesions ranging from tumour like lesions to benign and malignant tumours. Our study concluded that squamous cell carcinoma was the most common malignant lesion of oral cavity. Histopathology is an important tool in the diagnosis and management.

\section{ACKNOWLEDGEMENT}

We express our sincere thanks to the department of Otorhinolaryngology of SMGS Hospital, Jammu for sending us the specimens of oral cavity for our study and also to the technical staff of histopathology section of department of pathology for their support.

\section{REFERENCES}

[1] Shah J, Patel S, Singh B. Oral cavity. In: Head and neck surgery and oncology. $4^{\text {th }}$ edn. China: Elsevier 2007: p. 232-40.

[2] Elango JK, Gangadharan P, Sumithra S, et al. Trends of head and neck cancers in urban and rural India. Asian Pac J Cancer Prev 2006;7(1):108-12.

[3] Madani AH, Jahromi AS, Dikshit M, et al. Risk assessment of tobacco types and oral cancer. Am J Pharmacol Toxicol 2010;5(1):9-13.

[4] Gupta PC, Ray CS. Smokeless tobacco and health in India and South Asia. Respirology 2003;8(4):419-31.

[5] Petersen PE. Strengthening the prevention of oral cancer: the WHO perspective. Community Dentistry Oral Epidemiology 2005;33(6):397-9.

[6] Poh CF, Samsung NG, Berean K, et al. Biopsy and histopathologic diagnosis of oral premalignant and malignant lesions. J Can Dent Aaaoc 2008;74(3):283-8.

[7] Palve DH, Tupkari JV. Clinicopathological correlation of micronuclei in oral squamous cell carcinoma by exfoliative cytology. J Oral Maxillofac Pathol 2008;12(1):234-6.

[8] Senguven B, Baris E, Yildirim B, et al. Oral mucosal lesions: a retrospective review of one institution's 13 year experience. Turk J Med Sci 2015;45(1):241-5.

[9] Pudusaini S, Baral R. Oral cavity lesions: a study of 21 cases. Int J Res Rev 2013;05:110-6.

[10] Modi D, Laishran RS, Sharma LDC, et al. Pattern of oral cavity lesions in a tertiary care hospital in Manipur, India. J Med Soc 2013;27(3):199-202.

[11] Mehta NV, Dave KK, Gonsai RN, et al. Histopathological study of oral cavity lesions: a study on 100 cases. Int J Res Rev 2013;05:110-6.

[12] Mehrotra R, Singh M, Kumar D, et al. Age specific incidence rate and pathological spectrum of oral cancer in Allahabad. Indian J Med Sci 2003;57(9):4004.

[13] Misra V, Singh PA, Lal N, et al. Changing pattern of oral cavity lesions and personal habits over a decade: hospital based record analysis from Allahabad. Indian J Community Med 2009;34(4):321-5.

[14] Hassawi BA, Ali E, Subhe N. Tumours and tumour like lesions of the oral cavity. A study of 303 cases. Tikrit Med J 2010;16(1):177-83.

[15] Sharma P, Gupta K, Saini S, et al. A study of clincopathological spectrum of oral cavity lesions at a tertiary care hospital. JMSCR 2018;6(4):267-76.

[16] Kosam S, Kujur P. Pattern of oral cavity lesion. A retrospective study of 350 cases. Int J Sci Stud 2016;4(3):65-9.

[17] Durazzo MD, De Araujo CE, Jde BNS, et al. Clinical and epidemiological features of oral cancer in a medical school teaching hospital from 1994 to 2002: Increasing incidence in women, predominance of advanced local disease and low incidence of neck metastases. Clinics (Sao Paulo) 2005;60(4):293-8. 
[18] Bhattacharjee A, Chakraborty A, Purkaystha P. Prevalence of head and neck cancers in the north eastan institutional study. Indian J Otolaryngol Head Neck Surg 2006;58(1):15-9.

[19] Bal MS. A clinico-pathological study of 200 cases of oral cavity lesions. Res J Pharm Biol Chem Sci 2014;5(6):1035-40.
[20] Manjari M, Popli R, Paul S, et al. Prevalence of oral cavity, pharynx, larynx, nasal cavity malignancies in Amritsar, Punjab. Indian J Otolaryngol Head Neck Surg 1996;48(3):191-5.

[21] Shah PY, Patel RG, Prajapati SG. Histopathological study of malignant lesions of oral cavity. Int J Med Sci Public Health 2017;6(3):472-8. 